\title{
Research on the Influence of Real Estate Listed Enterprises to Fulfill Social Responsibility on Enterprise Growth
}

\author{
liu fu $\min ^{1}$, Ding wei tong ${ }^{2 *}$ \\ ${ }^{1}$ School of Management, Xi'an University of Science and Technology, Wild Goose Pagoda, Xi'an, China \\ ${ }^{2}$ School of Management, Xi'an University of Science and Technology, Wild Goose Pagoda, Xi'an, China \\ Email:a1425476565@qq.com \\ $b * 2529426585 @ q q . c o m$
}

\begin{abstract}
This paper combed the first social responsibility related to the growth of all kinds of research at home and abroad and combining the current our country real estate industry present situation and the social responsibility fulfillment influence mechanism and the research hypothesis is put forward, and then based on the stakeholder theory, shareholders, creditors, community, employees, government five stakeholders as corporate social responsibility (single variable, select the company size, profitability, operation ability, debt paying ability, expand capacity, human resources six as enterprise growth evaluation system, selection of listed companies time as control variables. Then design the index and build the model. Finally, according to the impact of corporate social responsibility on the current growth of variable correlation analysis and multiple regression analysis, according to the research conclusions, combined with China's national conditions and industry characteristics, this paper put forward reasonable suggestions for the government and enterprises. Expect to play a certain role in macroscopic policy and industry development.
\end{abstract}

Keywords: Real estate enterprise, Stakeholders, Social responsibility, grow

\section{THEORETICAL ANALYSIS AND RESEARCH HYPOTHESIS}

Based on the previous research system and methods, this study combined with the actual situation of listed real estate enterprises in China, to explore the relationship between the growth of Chinese real estate enterprises and their social responsibility under the existing domestic economic environment and background system. Based on the literature and case studies, this paper attempts to prove from the perspective of stakeholders that corporate social responsibility has a positive impact on corporate growth. Furthermore, enterprises are encouraged to actively undertake social responsibility, so that they understand that social responsibility is the essence of their own survival and development needs, and is an indispensable part of their own healthy development.

Ye Chengang and Cao Bo (2008) analyzed and studied the evaluation system of corporate social responsibility from the perspective of stakeholders, and then established a social responsibility evaluation system based on shareholders, investors, employees, competitors, society, government and business partners [1].

The CSR index system established by Peng Jing (2006) includes the responsibilities of enterprises to a series of stakeholders such as investors, employees, consumers, sustainable development of enterprises and public welfare donations. Specific indicators include: employment contribution, corporate tax record, corporate credit record, donation-income ratio, social contribution rate, etc., all of which are the key factors to evaluate the degree of social responsibility [2].

Wang Qiang (2003) took profit growth rate, capital growth rate, sales revenue growth rate, capital preservation and appreciation rate, output value growth rate, foreign exchange earning rate and personnel growth rate as factors affecting enterprise growth. Real number comparative analysis, trend analysis and ratio analysis are carried out to confirm different growth types of enterprises, including steady growth, out-of-control growth, excessive growth, cyclical growth, slow growth, 
responsible growth, etc. Finally, different growth models of enterprises are established [3].

Shang Mengmeng (2012) took private enterprises as samples and built an indicator system of corporate social responsibility based on stakeholder theory, and empirically concluded that corporate social responsibility has a significant positive impact on corporate growth [4].

He Chaozhen (2014) selected the data of small and medium-sized enterprises on the GEM over the years and used the least square method to conduct research, concluding that fulfilling social responsibility has a positive impact on growth [5].

\section{RESEARCH DESIGN}

Considering the enterprise society responsibility and comprehensive growth respectively composed of multiple stakeholders and a number of financial indicators, so "factor analysis" the social responsibility and growth indicators of this article, the principle, through the method of dimension reduction, namely the more intricate variables into several common factor analysis method. The idea is to divide the original variables into several categories based on the correlation standard, and each type of variable forms a common factor, which contains most of the information of the original variable, so as to convert the original many variables into fewer common factors. The specific indicators are as follows.

Table 1 Statistical table of empirical research variables

\begin{tabular}{ll}
\hline $\begin{array}{l}\text { The variable } \\
\text { name }\end{array}$ & Define \\
\hline
\end{tabular}

\section{Gro}

Factor analysis showed that

sha

Basic earnings per share $=$ net profit/number of common shares

Cre

EBITDA ratio $=$ EBITDA/total liabilities

Soc

Public welfare contribution rate $=$ total annual public welfare donation/net profit

Employee benefit rate $=$ cash paid to and for employees / Operating income

Emp

$$
\text { Operating income }
$$

Gov end of annual report /365

\section{EMPIRICAL ANALYSIS}

From the stepby analysis of regression results in Table 2 ,analysis of regression explanatory variables can be obtained. The results show that enterprise growth is significantly positively correlated with CSR and CRE1 at the level of $1 \%$, significantly positively correlated with SHA at the level of 5\%, significantly negatively correlated with EMP and AGE at the level of $1 \%$, but not significantly correlated with other variables. This indicates that after the inclusion of stakeholders, the performance of social responsibility of real estate enterprises still has a significant positive impact on the growth of the current period, and the listing time still has a significant negative impact. In terms of subdivision, real estate enterprises' fulfilment of social responsibilities to shareholders and creditors has a significantly positive impact on current growth, while the fulfilment of social responsibilities to employees has a significantly negative impact, while other variables have no significant impact.

Table 2 Multiple regression results

\begin{tabular}{lll}
\hline Variable & Coefficient & Prob. \\
\hline CSR & $0.267^{* *}$ & 0.000 \\
AGE & $-0.11^{* *}$ & 0.000 \\
Sha & $0.73^{*}$ & 0.036 \\
Cre1 & $0.019^{* *}$ & 0.000 \\
Cre2 & -0.014 & 0.510 \\
Soc & -0.252 & 0.557 \\
Emp & $-0.014^{* *}$ & 0.000 \\
Gov & 0.33 & 0.540 \\
C & $0.416^{* *}$ & 0.000 \\
& 0.592 & \\
\hline
\end{tabular}


$\mathrm{R}^{2}$ Adjust the

0.581

$\mathrm{F}$

$84.622^{* *}$

0.000

\section{THE RESEARCH CONCLUSION}

Based on the perspective of stakeholders, this paper discusses the impact of corporate social responsibility on growth, so that enterprises can realize that taking social responsibility is not a heavy burden for enterprises, but also can create a good environment for the growth of enterprises, so as to guide enterprises to take social responsibility actively. The listed companies in the real estate industry studied in this paper construct comprehensive indicators of corporate social responsibility and corporate growth through factor analysis. The single variable and comprehensive index of corporate social responsibility are taken as independent variables and the comprehensive index of corporate growth is taken as dependent variable to empirically study the impact of corporate social responsibility on corporate growth. To sum up, we can draw a conclusion, and then we will make a brief analysis and summary.

(1) The performance of the comprehensive index of social responsibility of real estate enterprises synthesized by the factor analysis method in the current period has a significant positive impact on the growth of real estate enterprises in the current period. After considering the factor of hysteresis, it is found that enterprises still have a positive impact. This indicates that although improving the current CSR performance of real estate enterprises will consume certain financial and human resources, it can significantly enhance the growth of real estate enterprises in the current period.

(2) Most single variables of corporate social responsibility are significantly positively correlated with the growth of the current period. According to the classification of stakeholders, real estate corporate social responsibility can be divided into social responsibilities to shareholders, employees, creditors, government and society. In order to explore the impact and differences of real estate enterprises' performance of fulfilling social responsibilities to various stakeholders on their growth. We add social responsibility performance indicators for various stakeholders into the regression model of the impact of comprehensive social responsibility performance of real estate enterprises on their growth. Regression results show that from the point of the current social responsibility performance, real estate enterprises to fulfill the social responsibility of the creditors and shareholders has a positive significant influence on the growth, of real estate enterprises to fulfill their social responsibility has a significant negative effect on the growth, to fulfill the social responsibility of the government have a positive influence on the growth, but not significant. Fulfilling social responsibility has a negative impact on its growth, but it is also not significant. After taking into account the lag, except that the positive influence of shareholders increases significantly, and the social responsibility of fulfilling the society changes from negative to positive, the rest is the same as that of the current period.

\section{POLICY RECOMMENDATIONS}

\subsection{Suggestions to the Government}

Improve relevant laws and regulations. Government departments should formulate the minimum standards for the implementation of social responsibility of real estate enterprises, and establish the corresponding social responsibility file system, early warning mechanism and credit evaluation system. Appropriate economic incentives or preferential policies will be given to enterprises that actively undertake social responsibilities. More preferential tax policies will be given to enterprises that pay taxes in full and on time according to law and are enthusiastic about public welfare undertakings. On the contrary, for enterprises that ignore social responsibility and infringe on stakeholders, the government should increase penalties, with a fine far higher than the illegal gains, so as to urge enterprises to consciously undertake social responsibility and improve their awareness of fulfilling their social responsibilities.The information disclosure system of corporate social responsibility should be improved. At present, China's corporate social responsibility report lacks a unified format, and only a small number of enterprises disclose it in detail. Under the pressure of public opinion, many enterprises only simply release information related to social responsibility, and most of them have never even released their social responsibility report.If the social responsibility report is not disclosed in detail, the market will not be able to fully understand the performance of the enterprise, which will lead to the lag of information of stakeholders and damage to the interests of the public. Therefore, reporting standards should be formulated in detail, requiring enterprises to improve information transparency, carry out more social responsibility work, and disclose relevant work results and operation data.Establish a corporate social responsibility supervision platform. Since the concept of social responsibility is three-dimensional, it is difficult for the general public to know whether an enterprise has fulfilled its obligations at the first time. Therefore, government departments should set up a corporate social responsibility supervision platform and give praise and public praise to enterprises that have made contributions to social welfare. At the same time, enterprises with poor housing quality, property environment and reputation will be exposed and severely punished and publicized through the platform, so that 
stakeholders can get to know the enterprises in time and create a fair and good environment for enterprises to fulfill their social responsibilities in a fair manner.

\subsection{Suggestions to enterprises}

Although the study conclusion shows that performance of the employees, growth has a negative influence on corporate social responsibility, but the real estate is a comprehensive industry, the number of employees and the species is numerous, no matter a gleam of grass-roots staff or middle technical backbone, is an integral part of enterprise development, so the real estate should be strengths, meet the reasonable needs of employees, such as the salary system and the growth of enterprise performance, stimulate staff's work enthusiasm and sense of responsibility, realize the employee benefit and enterprise win-win effect in the development of the common development. In this way, the turnover rate can be reduced, making it more valuable for enterprises to fulfill their social responsibilities to employees. Set up internal social responsibility supervision institutions, so that real estate enterprises can fully consider the interests of stakeholders and improve the corporate governance structure from the perspective of corporate governance. The essence of corporate governance is to coordinate the responsibility and right relations among stakeholders. The extended significance of corporate social responsibility lies in that an enterprise is a carrier of interest conflict and cooperation among different stakeholders, and the process of an enterprise undertaking social responsibility is the process of realizing the interests of stakeholders. Set up a "Stakeholder Committee" composed of representatives from all stakeholders of the real estate enterprise. The functions of this organization mainly include three aspects: collecting and sorting out the requirements of different stakeholders on the enterprise, and passing them to the board of directors in a timely manner; Communicate the decisions of the board of directors to stakeholders in a timely manner; Supervise management's implementation of the board's decisions. By setting such an institution in the corporate governance structure, real estate enterprises can effectively supervise their decisions, ensure that the decisions they make meet the interest requirements of most stakeholders, and thus promote their commitment to social responsibility.

\section{CONCLUSION}

For the society, the state does not reward enterprises for large philanthropic efforts, and does not publicize the enterprises that contribute, so that the good deeds done are not known by others. Although the enterprise has fulfilled its social responsibility, it has failed to produce substantial help to the enterprise, which has a great relationship with the propaganda of social responsibility in our country. After all, charitable donations are not mandatory. They are all based on the corporate spirit of public welfare. It would be heart-rending if no one remembered a good deed done.

\section{REFERENCES}

[1] Ye Chengang, Cao Bo Construction of Corporate Social Responsibility Evaluation System [J], Finance and Accounting Monthly (Comprehensive),2008,6.

[2] Peng Jing, Research on Fuzzy Evaluation of Corporate Social Responsibility,[D], Sichuan University,2006.

[3] Wang Qiang. Research on Firm Growth Model from the Perspective of Growth Analysis, Modern Accounting,2003,(8):28-35.

[4] Shangmengmeng. A Study on the Correlation between Social Responsibility and Corporate Growth of Private Enterprises in China [D]. Shandong: Ocean University of China,2012.

[5] He Chaozhen. A Study on the Correlation between Social Responsibility and Growth of Small and Medium-sized Enterprises [D]. Hunan: Central South University,2014 